East African Medical Journal Vol. 87 No. 3 March 2010

PREVALENCE AND PATTERN OF EARLY CHILDHOOD CARIES AMONG 3-5 YEAR OLDS IN KIAMBAA, KENYA

N. W. Njoroge, BDS (Nbi), MDS (Nbi), A. M. Kemoli, BDS (Nbi), MSc (Amsterdam), Department of Paediatric Dentistry and Orthodontics and L. W. Gatheche, BDS (Nbi), MPH(Nbi), Department of Periodontology, Community, and Preventive Dentistry, School of Dental Sciences, University of Nairobi, P.O. Box 19676-00200, Nairobi, Kenya

Request for reprints to: Dr. N. W. Njoroge, Department of Paediatric Dentistry and Orthodontics, School of Dental Sciences, University of Nairobi, P.O. Box 19676-00200, Nairobi, Kenya

\title{
PREVALENCE AND PATTERN OF EARLY CHILDHOOD CARIES AMONG 3-5 YEAR OLDS IN KIAMBAA, KENYA
}

\author{
N. W. NJOROGE, A. M. KEMOLI and L.W. GATHECHE
}

\begin{abstract}
Objective: To determine the prevalence and pattern of early childhood caries among three to five year olds.

Design: This was a descriptive, cross-sectional study.

Subjects: A total of 336 children aged 3-5 years.

Setting: Pre-schools in Kiambaa division, Kiambu District, Kenya.

Results: Slightly over a half, $201(59.5 \%)$ had dental caries. The mean decayed, missing and filled teeth $(\mathrm{dmft})$ was $2.46 \pm 2: 3.2$ with the greatest component $(95 \%)$ being decayed teeth. The mandibular deciduous molars and the maxillary incisors were the most frequently carious teeth.

Conclusions: The prevalence of early childhood tumours in Kiambaa was $59.5 \%$. The mandibular deciduous molars and maxillary incisors had the highest caries frequency.
\end{abstract}

\section{INTRODUCTION}

Early childhood caries (ECC) is the presence of one or more decayed (noncavitated or cavitated lesions), missing (due to caries), or filled tooth surfaces in any primary tooth in a child aged 71 months or younger $(1,2)$. The term was first suggested at a 1994 Centres for Disease Control and Prevention workshop (3).

ECC has also been described as nursing caries, nursing bottle syndrome, night bottle mouth, and baby bottle tooth decay (4). ECC has two variants: nursing caries and rampant caries. The difference between the two variants is the involvement of mandibular incisors in rampant caries as opposed to nursing caries. ECC is a result of the interaction of cariogenic bacteria, fermentable carbohydrates and susceptible teeth within appropriate time (5). Frequent consumption by the child of foods containing fermentable carbohydrates withoutgood oral hygiene increases the risk of caries (6). Epidemiological studies on ECC have indicated varied results. In his review, Milnes (7) found that the highest prevalence of ECC was in Africa and South East Asia.

ECC can lead to both short and long term consequences. In the short term, the child may experience pain during feeding and subsequent irreversible pulp damage that may lead to premature loss of teeth. This may in the long term predispose the child to the development of malocclusion in the succeeding permanent dentition besides the increased risk of developing caries in the permanent dentition (8) and a diminished oral health related quality of life (10).

\section{MATERIALS AND METHODS}

The study was conducted in Kiambaa, one of the five divisions of Kiambu district in Central Province, Kenya. The area borders the Kenyan capital city and was chosen due to its accessibility. In addition, residents in the area were likely to be of a diverse socio-economic status.

This was a descriptive cross-sectional study of 3-5 year old children. Stratified random sampling method was used to select public and private schools. It was deemed necessary to stratify the schools because the children were thought to represent different socioeconomic groups. Schools were selected from each category using a table of random numbers until the sample size was obtained. A total of 336 children wereexamined for caries using WHOguidelines (11). The children were examined sitting on a cushion on the examiner's lap. Cotton roll was used to remove plaque from the surfaces of the teeth. The teeth were then examined for caries using a dental mirror and probe. Demographic data collected included child's date of birth, gender and type of school attended. The age of the child was recorded as per the age at their last birthday and categorised as 3, 4 or 5 years. Data collected was entered and analysed using Statistical Package for Social Sciences (SPSS) version 12.0.1 for computer windows software. Univariate analyses 
were performed using Chi square statistics with $p$ value $<0.05$ considered statistically significant.

\section{RESULTS}

Socio-demographic characteristics: Three hundred and forty three children were recruited to participate in the study. Seven were uncooperative and were not examined. Out of 336 children examined, 169 (50.3\%) were male and 167 (49.7\%) were female. About 222 $(65.7 \%)$ of the children were from private pre-schools while the rest, 114 (34.3\%) children were from public pre-schools. The age range was 3-5 years with a mode of 5 years (Figure 1), and the mean-age was $4.61 \pm 2: 0.58 \mathrm{SD}$. There was no significant statistical difference between age of the male and female children $(\mathrm{p}=0.394)$.
Early childhood caries (ECC): The overall mean decayed, missing and filled teeth (dmft) was $2.46 \pm$ 3.21. The mean number of decayed teeth was $2.36 \pm$ 2.3.12, while the missing teeth and filled teeth was $0.08 \pm 0.41$ and $0.02 \pm 0.19$ respectively (Table 1 ). Slightly over half $201(59.5 \%)$ of the children had dental caries. The prevalence of caries by age was $47 \%, 55 \%$ and $63 \%$ for the 3,4 and 5 year old children respectively. The prevalence of caries was higher among the boys $(64.5 \%)$ compared to the girls (54.4\%) but the difference was not statistically significant $(\mathrm{p}=0.060)$. Notably, there was a significantly higher prevalence of caries among children from private preschools compared to those from public preschools $(\mathrm{P}=0.001)$.

Figure 1

Age and gender distribution of children $(n=336)$

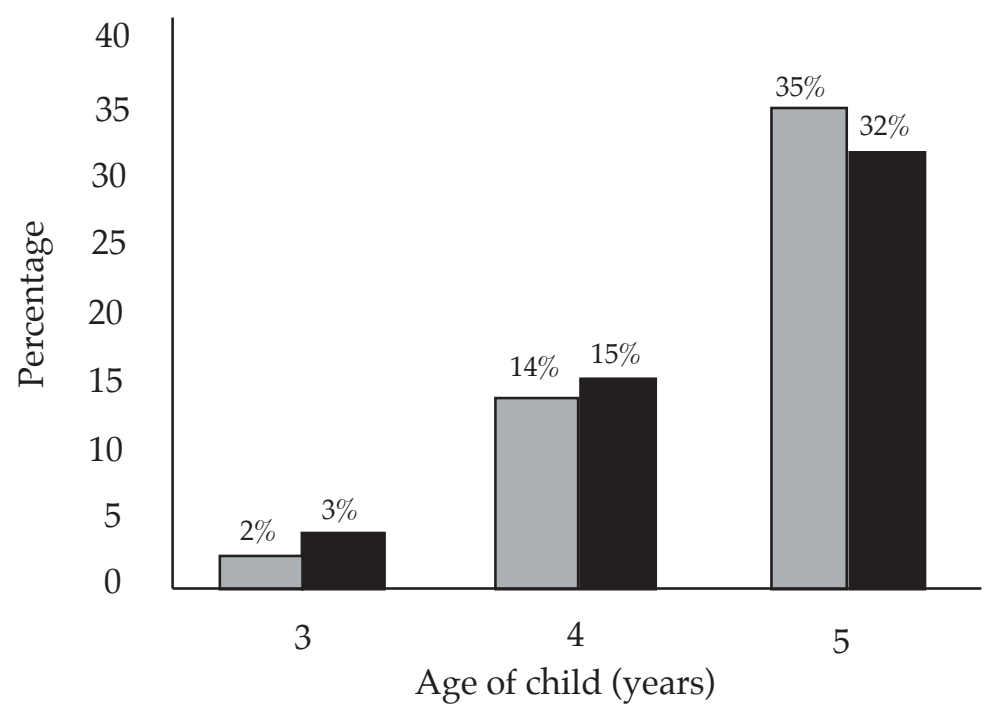

Table 1

Caries experience by gender and age of child $(n=336)$

\begin{tabular}{clllllll}
\hline $\begin{array}{l}\text { Age } \\
\text { (years) }\end{array}$ & Gender & No. & $\begin{array}{l}\text { Decayed } \\
(\mathrm{d}) \text { mean }\end{array}$ & $\begin{array}{l}\text { Missing } \\
(\mathrm{m}) \text { mean }\end{array}$ & $\begin{array}{l}\text { Filled (f) } \\
\text { mean }\end{array}$ & dmft & SD \\
\hline 3 & Male & 6 & 0.83 & 0.00 & 0.00 & 0.83 & 1.17 \\
& Female & 11 & 1.64 & 0.00 & 0.00 & 1.64 & 2.73 \\
& Sub-total & 17 & 1.35 & 0.00 & 0.00 & 1.35 & 2.29 \\
\multirow{4}{*}{4} & Male & 47 & 2.43 & 0.04 & 0.04 & 2.51 & 3.98 \\
& Female & 49 & 2.06 & 0.02 & 0.04 & 2.12 & 2.83 \\
& Sub-total & 96 & 2.24 & 0.03 & 0.04 & 2.31 & 3.43 \\
5 & Male & 116 & 2.68 & 0.09 & 0.00 & 2.78 & 3.24 \\
& Female & 107 & 2.29 & 0.12 & 0.02 & 2.43 & 3.11 \\
& Sub-total & 223 & 2.49 & 0.11 & 0.01 & 2.61 & 3.17 \\
& Male & 169 & 2.54 & 0.08 & 0.01 & 2.63 & 3.42 \\
& Female & 167 & 2.18 & 0.08 & 0.02 & 2.29 & 2.99 \\
\hline
\end{tabular}


Pattern of ECC: Overall, $40.5 \%$ of the children in the study were caries free. Among the $59.5 \%$ of the children with carious lesions, $32 \%$ had 1 to 3 lesions, $16 \%$ had 4 to 6 lesions, $8 \%$ had 7 to 9 lesions while only $4 \%$ of the children had more than 10 lesions. The distribution of carious lesions was different for both arches. The deciduous teeth in the maxillary arch were more frequently affected by caries than the teeth in the mandibular arch. However, overall mandibular molars were the most affected by caries $319(40 \%)$ followed by the maxillary molars $202(25 \%)$ and maxillary incisors $198(25 \%)$. The least affected teeth were the maxillary deciduous canines $17(2 \%)$ (Figures 2a and 2b). Overall frequency of caries by tooth type was deciduous molars $521(65.7 \%)$, incisors $225(28.4 \%)$ and canines $47(5.9 \%)$.
Of the 343 children recruited to participate, 336 were examined whereas seven were uncooperative. About two-thirds of the children attended private preschools. The higher number of children in private preschools compared to public subsidized pre-schools could be due to the fact that pre-school education is generally not funded by the Government of Kenya.

The prevalence of caries in the study population $(59.5 \%)$ was less than that reported by Ngatia et al. $(63.5 \%)$ among 3-5 year olds in Nairobi (12). The lower prevalence in the current study may reflect differences in the study settings. The present study was done in a rural area while Ngatia et al. was in an urban setting. The prevalence of caries in the present study was $47 \%, 55 \%$ and $63 \%$ for the 3,4 and 5 year olds respectively which compared closely to that

Figure 2 a

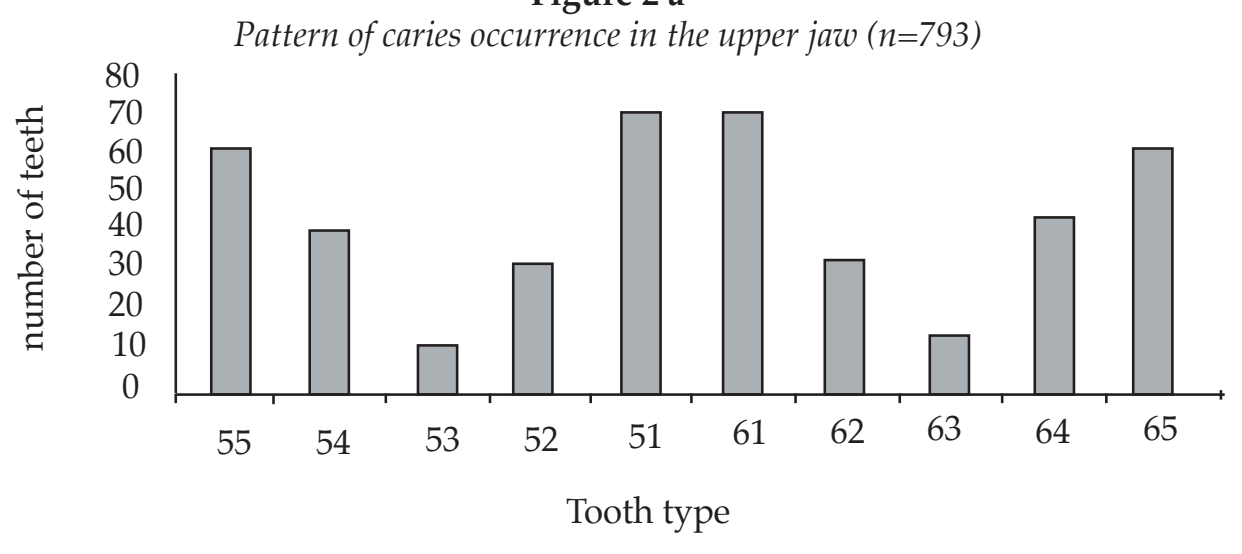

Figure $2 \mathbf{b}$

Pattern of carries occurrence in the lower jaw $(n=793)$

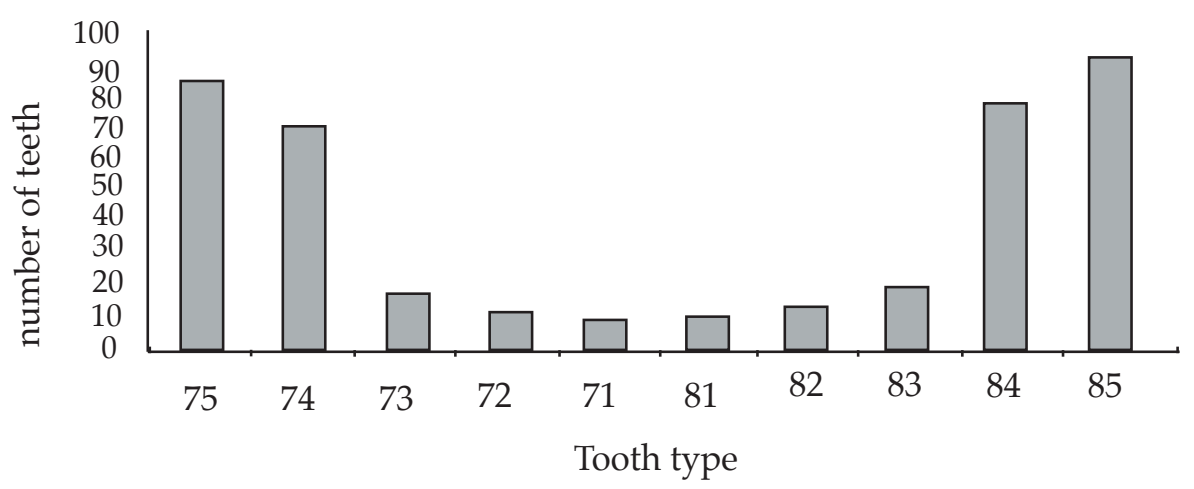

\section{DISCUSSION}

The broad objective of the current study was to determine the prevalence and patterns of ECC among 3-5 year old preschool children in Kiambaa Division. The design adapted was a descriptive cross- sectional study. The choice of the 3-5 year age bracket was in line with the definition of ECC. reported in Uganda by Kiwanuka et al. (13) of 45\%, $59 \%$ and $65 \%$ in the same age group. The higher caries prevalence with increasing age of child may be due to increased (cumulative) time of exposure of the deciduous dentition to cariogenic foods. Thus increasing age of the child seemed to be a risk factor of caries development in deciduous dentition. 
The type of school attended by the child appeared to affect the caries predisposition. The current study reported a significantly higher prevalence of caries among children attending private pre-schools. The children were probably from relatively higher socioeconomichouseholds compared to those from public preschools. Although this was not confirmed, it is likely that children from more affluent households with greater disposable income could afford to purchase cariogenic snacks more often.

Dental caries experience was assessed using the $\mathrm{dmft}$ index. The mean $\mathrm{dmft}$ in the current study was $2.4 \pm 3.21$ with the decayed component contributing $95 \%$ of the score.

Other studies in Africa have reported similar findings in caries experience. In Uganda and South Africa, studies have reported mean $\mathrm{dmft}$ values of 2.6 and 2.9 respectively among 3-5 year old children $(13,14)$. It is noteworthy that the decayed component contributed the largest proportion of the $\mathrm{dmft}$ in the current study, implying that majority of the carious lesions were untreated. Lack of adequate and accessible dental facilities and manpower especially in the Government hospitals may be part of the reason. The high cost of dental treatment in private clinics may also limit access to services.

Although, the boys had a higher $\mathrm{dmft}(2.63 \pm 3.4)$ than the girls $(2.29 \pm 3.0)$, the difference was not statistically significant.

The most frequently affected teeth by caries were deciduous mandibular molars followed by maxillary incisors and molars. This pattern seems to mimic nursing caries. Previous studies in Nairobi reported similar patterns with deciduous maxillary incisors, mandibular and maxillary molars being most affected by caries (12)

In conclusion, the prevalence of ECC among the 3-5 year olds in Kiambaa, Kenya was $59.5 \%$. The mean dmft was 2.4 \pm 3.2 with the decayed component contributing $95 \%$ of the score. The mandibular deciduous molars and the maxillary incisors were the most frequently affected teeth.

\section{ACKNOWLEDGEMENTS}

To Dr. A. Hussein (University of Nairobi, Dental Hospital) for his assistance during calibration, the staff, parents and children of the schools visited for their cooperation and A. Lakati from Kenya Medical Training College for her assistance in data analysis.

\section{REFERENCES}

1. Kaste, L.M., Drury, T.F., Horowitz, A.M. and Beltran, E. An evaluation of NHANES III estimates of early childhood caries. J. Pub. Hlth Dent. 1999; 59: 198-200.

2. Drury, T.F., Horowitz, A.M., Ismail, AI., et al. Diagnosing and reporting early childhood caries for research purposes. J. Pub. Hlth. Dent. 1999; 59: 192-197.

3. Kaste, L.M. and Gift, H.C. Inappropriate infant bottle feeding. Status of the healthy people 2000 objective. Arch. Pediatr. Adolesc. Med. 1995; 149: 786-791.

4. Reisine, S. and Douglass, J. M. Psychosocial and behavioral issues in early childhood caries. Comm. Dent. Oral Epidemiol. 1998; 26(1 Suppl): 32-44.

5. Loesche, W.J.Dental caries: a treatableinfection. Grand Haven, Mich:Automated Diagnostic Documentation, Inc; 1993

6. Marino, R., Bonze, K., Scholl, T. and Anhalt, H.Nursing bottle caries: characteristics of children at risk. Clin. Paediatr. 1989; 28: 129-131.

7. Milnes, A.R. Description and epidemiology of nursing caries. J. Pub. Hlth Dent. 1996; 56: 38-50.

8. Gray, M.M., Marchment, M.D. and Anderson, R.J. The relationship between caries experience in deciduous molars at 5 years and in first permanent molars of the same child at 7 years. Comm. Dent. Hlth. 1991; 8: 3-7.

9. O'Sullivan, D.M. and Tinanoff, N. The association of early childhood caries patterns with caries incidence in preschool children. J. Pub. Hlth Dent. 1996; 56: 81-83.

10. Low, W., Tan, S. and Schwartz, S. The effect of severe caries on the quality of life in young children. Pediatr. Dent. 1999; 21: 325-326.

11. World Health Organisation Oral HealthSurveys, Basic Methods, 4th Edn. Geneva: World Hlth. Org. 1997.

12. Ngatia, E. M., Imungi, J. K., Muita, J. W. and Ng'ang'a, P.M. Dietary patterns and dental caries in nursery school children in Nairobi, Kenya. East Afr. Med. J. 2001; 78: 673-677.

13. Kiwanuka, S.N., Astrm, A.N. and Trovikta. Dental caries experience and its relationship to social and behavioural factors among 3-5 year old children in Uganda. Int. J. Paed. Dent. 2004; 14: 336-346.

14. Khan, M.N. and Cleaton-Jones P.E. Dental caries in African preschool children: social factors as disease markers. J. Pub. Hlth Dent. 1998; 58: 7-11. 